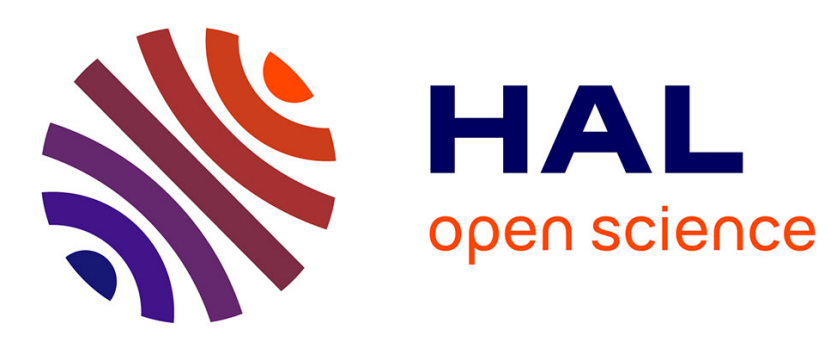

\title{
Social Media and Social CRM
}

Antonín Pavlíček, Petr Doucek

\section{To cite this version:}

Antonín Pavlíček, Petr Doucek. Social Media and Social CRM. 10th International Conference on Research and Practical Issues of Enterprise Information Systems (CONFENIS), Dec 2016, Vienna, Austria. pp.77-87, 10.1007/978-3-319-49944-4_6. hal-01630534

\section{HAL Id: hal-01630534 https://hal.inria.fr/hal-01630534}

Submitted on 7 Nov 2017

HAL is a multi-disciplinary open access archive for the deposit and dissemination of scientific research documents, whether they are published or not. The documents may come from teaching and research institutions in France or abroad, or from public or private research centers.
L'archive ouverte pluridisciplinaire HAL, est destinée au dépôt et à la diffusion de documents scientifiques de niveau recherche, publiés ou non, émanant des établissements d'enseignement et de recherche français ou étrangers, des laboratoires publics ou privés. 


\title{
Social media and social CRM
}

\author{
Antonín Pavlíček ${ }^{1}$, Petr Doucek ${ }^{1}$ \\ ${ }^{1}$ University of Economics, Prague, 3 W. Churchill sq. \\ 13067 Prague, Czech Republic \\ \{antonin.pavlicek, doucek\}@vse.cz
}

\begin{abstract}
The main aim of the paper is to analyse social CRM, specifically Facebook communication of mobile operators in the United States, the Czech Republic, and France to examine the state of social customer care on social networking sites and consider possibilities, need for automatization and improvement of EIS. The analysis is based on messages and answers posted on Facebook pages and measuring the response time on over 1.3 million unique questions. It identifies trends, looks for certain repeating patterns or correlations and as a result offers a comprehensive report on the current use of social media as a channel for customer care amongst mobile operators. The theoretical background will also propose an advice on how to maintain a healthy relationship with customers on social networks and add a real value both for customers and company.
\end{abstract}

Keywords: Customer Relationship Management, Customer Care, Social Media, Social Networking Sites, Social CRM, Enterprise Information System, Facebook, Good Practice, Telecommunications, Mobile Operators, Response Time, Czech Republic, France, USA

\section{Introduction}

There is no doubt that social networking sites (SNS) have recently become new communication standard in e-society [4]. Thanks to its versatility SNS can be used to find the job [2], romantic partner, latest gossip [5], play interactive games [12] or just have private [10] conversation with friends and acquaintances [9]. Facebook is the main on-line community communication channel [13] not only for teenagers or young college students but also for the vast majority of working population in developed countries. Its growing popularity resulted in more than 1.65 billion Facebook users [7]. Companies follow this trend by investing into proper maintenance of their profiles on social networks but quality social media content is just one part of success. The other part - maybe even more important - makes the core of this paper: interaction with customers.

Contacting a company over SNS is just one or two clicks away. It is fast, free and public so anybody can see the response verified by thousands of visitors, who can 
assess the answer and judge the company. That is the main reason why customer care on social networks is becoming crucial.

\section{$2 \quad$ CRM and Social Media}

A systematic review of the state of the customer relationship management (CRM) [11] defines the customer relationship management as "The overall process of building and maintaining profitable customer relationships by delivering superior customer value and satisfaction with the goal of improving the business relationships with customers. Also, it is the strongest and the most efficient approach to maintaining and creating the relationships with customers." A company should care about its customer by answering their request and solving their problems. CRM can also involve in business intelligence factors by observing the expectations of the customers. Both abovementioned goals can be supported by social media.

The modern approach to CRM began in the 1990s with Sales Force Automation (SFA) that enabled companies to hone their sales processes and boost productivity. CRM continues to evolve and by the end of the century the world's first mobile CRM solution is introduced, followed by the first ever Software-as-a-Service (SaaS) CRM product.

Since the spreading of the internet in the beginning of the 21 st century, customers have become more informed about the prices, the products, the services, the competitors and as a consequence are more demanding. Another point was described by Gilles Babinet [1], who explained that nowadays the worth of a product comes more from the additional services it can provide, rather than the real technical capacities. He called that the "revolution in the worth process for the companies". Companies begin to see CRM as a way to manage all business relationships via a single platform. However, companies had difficulties at the time calculate return of investments [6] and to adapt to this new demands and often did not get the stake of a performant CRM software or on the opposite wanted to develop a lot of functionalities but without strategy and as a result they got too many data that they did not know how to use.

During the recent years, successful companies have built a real CRM strategy: especially companies that grew up very fast, such as Uber, Airbnb, Booking, Apple ... usually offer an amazing customer care. Indeed, companies that began succeeding were working both front and back systems and their goals were to link these systems together, as a system that can be used by customers and business partners. The CRM scene is expected to be worth $£ 36.4$ billion by 2017 according to Gartner [3].

We can identify two main ways to deal with customer care: customer interactions / contact software (CIS) and Customer Relationship Management (CRM) software. CIS is more flow oriented whereas the CRM system really focusses on the customer.

A customer interactions software enables to optimize the dispatch of the demand stream (input) accordingly to the available resources to deal with these requests. It is typically what is going on in call centres but some developers are trying to apply the same procedures in chat, emails or social network. The main goal is to split the depends in order to organize the waiting line in an optimal way, with more or less so- 
phisticated allocation rules. The operating is very simple: when a customer contacts company, no matter how he does it, a ticket is created. Then the ticket is handled automatically and randomly by any employee.

A customer relationship management software tries to put the customer in the centre of the process - it creates a database where all the information are gathered: emails, phone calls, mails, fax... It fits especially to the companies, which wish to know their clients in order to offer customized service and speech. Some CRM software also enable to allocate the request to the right customer adviser, according to its language and competencies.

In this respect we can point to two main advantages of a CRM software compared to a customer contacts software. First and foremost, CRM enables to follow the evolution of the client. That means a lot for the client as they really appreciate to be recognized and not only considered as numbers: the way of answering cannot be the same for a client that contact the company for the first or the fifth time on the same topic. Social media can enhance such individual approach. Secondly, the CRM software enables to enhance the knowledge about clients: customers want adapted answers for their request but also for the products and services that are offered. Gathered in the CRM software, the marketing department can also use them to analyse the desires of its customers. Feedback and verbatim are very precious sources for the marketing to identify new segments, social media are ideal partner for this.

Our paper focuses on the new possibilities of social communication, which emerged with the rise of Facebook, Twitter and other SNS, while trying to answer, whether and how Enterprise Information System (EIS) can be involved.

\subsection{Customer care on social networks: Social CRM}

Social Customer Relationship Management (SCRM) does not replace CRM but it extends its application field by integrating the data from social networks and other digital exchange places.

In March 2008 Comcast was one of the first companies to interact directly with the customers via Twitter. Social media marketing was beginning to grab the attention of organization as the use of Facebook began to spread rapidly through the world. Moreover, companies began to see the power of social media marketing to attract customers. In return, customers began to see how they could use the web to be able to express their thoughts about companies online: organizations became, therefore, aware that customers do not bring them feedback directly but instead post their opinion publicly online. In this respect, CRM vendors started to develop systems that would address the issue created by social networks.

After 2010, CRM begins to integrate all departments: the companies has understood that the concept of CRM is strategic and companies of all size implement CRM software. As a consequence, social CRM needs to be much more integrated into customer management systems and approach. Social CRM was estimated to comprise $8 \%$ of all global CRM spending during 2012, which has doubled since 2010, according to Gartner. [3] 


\section{Research Questions}

In our research we have, by observing actual events on SNS, tested limits of meaningful SCRM usage and whether/how Enterprise Information System (EIS) can be useful support tool. The paper seeks to find answers to the following research questions:

1. Is really Social CRM in practice used so extensively as claimed by theoretical studies?

2. What mood / sentiment on SNS prevails? Is the medium predominantly negative? How SCRM deals with it?

3. Doesn't Social CRM a create problems due to expected short response times? Should be the SCRM process automated or computer aided?

\section{$4 \quad$ Research Methodology}

We have decided to analyze mobile network operators (MNO) since this industry is closely connected with modern technologies, companies are quite big and rich, their product is commoditized so the marketing and CRM are of vital importance. Also, from the data perspective - MNOs usually dispose of large fan communities on Facebook and their customers often face plenty of - often repetitive- problems that need to be solved. We analyzed official Facebook pages of three leading, ${ }^{1}$ MNOs from the Czech Republic, France, and the United States (see Table 1) and collected public users' questions and all the answers with all possible metadata, primarily time of the answer and response, that might show us the current state of social customer care, its development over time, differences between countries and individual operators and finally usage of Facebook as a place to solve customers' problems.

Altogether, we have managed to legally download over 1.3 million unique questions with all of the consecutive reactions. Through six year period (2010 to 2015) we have measured the time that it took customer care staff to answer the question and even to answer the following questions and also absolute and relative totals of questions asked and answered as well as the difference between these two. As a factor representing the quality of the answer, we counted questions that were successfully solved by one reply and related this number to all answered questions. These data were related to the time of the day and months and years and tested for repeating patterns or interesting formations. Each factor is also compared by individual operators amongst each other and aggregated by countries.

For qualitative analysis, we have analyzed 100 most popular posts (Likes \& Shares) for each company ( $\mathrm{N}=900)$.

1 With one exception in the USA, where the largest one - Verizon - does not have its Facebok page opened for public posts. 
Table 1. Number of Fans and Followers on Facebook and Twitter as of November 2015 - in thousands (K) and millions (M) (authors)

\begin{tabular}{|c|c|c|c|c|c|c|c|c|c|}
\hline & \multicolumn{3}{|c|}{ Czech Republic } & \multicolumn{3}{|c|}{ France } & \multicolumn{3}{|c|}{ USA } \\
\hline & $\tilde{o}$ & 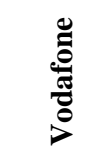 & 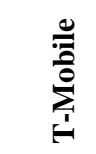 & $\frac{\mathscr{r}}{\widetilde{W}}$ & 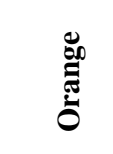 & 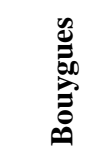 & 齐 & 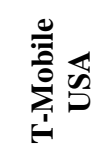 & ڤै \\
\hline FCB & $185 \mathrm{~K}$ & $183 \mathrm{~K}$ & $197 \mathrm{~K}$ & $927 \mathrm{~K}$ & $9.4 \mathrm{M}$ & $826 \mathrm{~K}$ & $5.8 \mathrm{M}$ & $5 \mathrm{M}$ & $2.1 \mathrm{M}$ \\
\hline TW & $8.5 \mathrm{~K}$ & $39 \mathrm{~K}$ & $5.5 \mathrm{~K}$ & $52.2 \mathrm{~K}$ & $123 \mathrm{~K}$ & $82 \mathrm{~K}$ & $711 \mathrm{~K}$ & $575 \mathrm{~K}$ & $345 \mathrm{~K}$ \\
\hline
\end{tabular}

\subsection{Data Gathering}

Facebook provides two different ways to gather data from their social network, either query language FQL or newer API called Graph API. Both of these meet our needs. There are many online tools for Facebook data analysis, in our case, however, there was no suitable solution on the market, as our requirements were a bit specific. So we have used Power Query - an extension for Microsoft Excel which has built-in support for gathering data from Facebook.

\subsection{Limitations}

Some operators do not have their Facebook page available for posting messages and rather use their own custom web application for customer care which makes impossible for us to analyse any desired information.

Also, the amount of fetched data might be limited by Facebook cut-off policy when carrying out too many requests consecutively. Due to this problem, there were a few minor gaps in downloaded data - estimated at 5\% - 10\% from the complete set.

Average response time could have been influenced by long-time unanswered posts later commented by other user and just then answered by MNO. Response time, in this case, would be extremely high - so we have removed those cases from calculations.

Minimal response values of the second and third answer were sometimes as low as one second - when clients' response is commented by someone else at the same time as by the operator itself - such records were also removed so they don't skew the results.

We were also a disappointed by Twitter's policy as it was originally planned to carry out the same research there. Unfortunately, their API does not provide full conversations with all the replies, which makes such kind of data mining impossible. 


\section{$5 \quad$ Results and discussion}

SCRM level was measured by the extent and delay of response to customers' stimuli. Table 2 shows the results for all MNOs, with the overall response rate is just about 23 percent (320.682 out of 1.367.586). On average, MNOs answered only every fourth question raised on SNS. The highest answer rate had Orange in France with $49 \%$ of answered questions. The worst response rate was observed with Sprint in the USA with $90 \%$ of unanswered questions.

Table 2. Overall Statistics (authors)

\begin{tabular}{|c|c|c|c|c|c|c|}
\hline & $\begin{array}{l}\text { Number } \\
\text { of Mes- } \\
\text { sages }\end{array}$ & $\begin{array}{l}\text { Questions } \\
\text { Without } \\
\text { Answer } \\
\end{array}$ & $\begin{array}{l}\text { Questions } \\
\text { Without } \\
\text { Answer } \\
\end{array}$ & $\begin{array}{l}\text { Average } \\
\text { Time }\end{array}$ & $\begin{array}{l}\text { Minimum } \\
\text { Time }\end{array}$ & $\begin{array}{l}\text { Maximum } \\
\text { Time }\end{array}$ \\
\hline $\mathrm{O} 2 \mathrm{CZ}$ & 79.063 & 53.295 & $67 \%$ & $4: 22: 44$ & 0:00:46 & 49:31:02 \\
\hline Vodafone CZ & 62.460 & 41.567 & $67 \%$ & $5: 49: 56$ & 0:00:38 & $128: 29: 18$ \\
\hline T-Mobile CZ & 35.599 & 22.525 & $63 \%$ & $3: 58: 48$ & 0:00:21 & $66: 36: 40$ \\
\hline Orange FR & 9.636 & 4.950 & $51 \%$ & $15: 51: 48$ & 0:00:49 & $73: 37: 52$ \\
\hline SFR FR & 25.996 & 15.583 & $60 \%$ & $31: 04: 42$ & 0:01:19 & $287: 59: 26$ \\
\hline $\begin{array}{l}\text { Bouygues } \\
\text { Telecom FR }\end{array}$ & 231.498 & 190.307 & $82 \%$ & 14:58:57 & 0:00:22 & $289: 16: 50$ \\
\hline ATT USA & 194.533 & 110.956 & $57 \%$ & 4:05:54 & 0:00:18 & $99: 22: 40$ \\
\hline $\begin{array}{l}\text { T-Mobile } \\
\text { USA }\end{array}$ & 318.315 & 236.641 & $74 \%$ & $1: 45: 55$ & 0:00:15 & $97: 54: 21$ \\
\hline Sprint USA & 410.486 & 371.080 & $90 \%$ & $8: 07: 19$ & 0:00:47 & $99: 53: 45$ \\
\hline SUM & 1.367 .586 & 1.046 .904 & $76,55 \%$ & & & \\
\hline Average & & & & 10:00:40 & 0:00:37 & 132:31:19 \\
\hline
\end{tabular}

\subsection{Incoming SCRM communication}

Total message chart (Fig. 1) shows total incoming communication activity from users (messages placed monthly on MNO's Facebook page) through six year period. 20.000 messages were surpassed in April, June and October 2013 by Sprint - with approximately two-thirds of cases were complaints and negative reactions. In comparison with T-mobile and AT\&T, Sprint had the worst positive / negative ratio. In France, the highest peak reached 13.297 messages in February 2012. Czech market peaked in May 2013 with 4.153 questions/comments.

Czech market is quite specific. There was the very slow beginning of customer care implementation on Facebook for all MNOs: Vodafone was the first one to use, promote and track Facebook in early 2011. Until today we can trace their difficult beginnings on Facebook - reflecting the fact, that innovations of IT in telecommunication causes a lot of unexpected situations - but surprisingly Vodafone CZ kept improving the quality of services, and reduced the problems. 
In January 2012 O2 CZ offered Facebook users chance to win mobile phones for free. That spurred the growth of active $\mathrm{O} 2$ customers and from that moment $\mathrm{O} 2 \mathrm{CZ}$ started to compete of Facebook with other providers. T-Mobile CZ and Vodafone CZ's total messages softly decline, but O2 took lead in January 2014 again, this time by harnessing the power of "influencers" who started big wave of interactions on O2 Facebook page with a lot of likes, shares, haters, and lovers and boosted total messages by onefifth every month.

Fig. 1. Total Message Count in Time (authors)

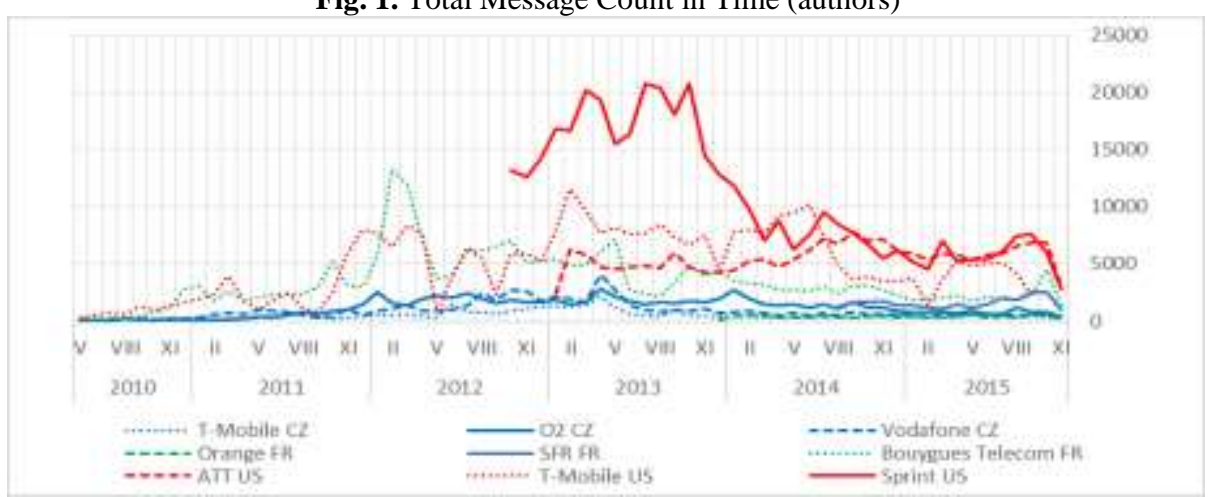

By the end of 2015, no MNO received more than 3.000 messages per month. Such reduction of the questions and answers can be explained by more "formal" behaviour and removing of the problems from Facebook pages, but still, there is enough data comparing the questions and helpfulness of answers that put T-Mobile as a dominant SCRM player. Sprint USA as the only provider in USA market couldn't handle the situation and restricted the rights of Facebook users to contribute on its page - practically acknowledging SCRM defeat.

\subsection{The frequency of SNS posts during day}

Figure 2 represents total aggregated number of questions asked and answered during each hour of a day. The highest amount of questions was asked expectedly on the USA market, as it is by far the largest one, between 11 a.m. and 9 p.m., peaking at 7 p.m. (58.781). Questions in France peaked at 21.103 during 11 a.m. and in the Czech Republic during the 1 p.m. (12.686).

On the other hand, it is not surprising that 4 a.m. is the time with an overly lowest number of questions common for all the markets. Question are not limited to business hours, we can witness customers asking the questions almost around the clock. 
Fig. 2. Questions During a Day

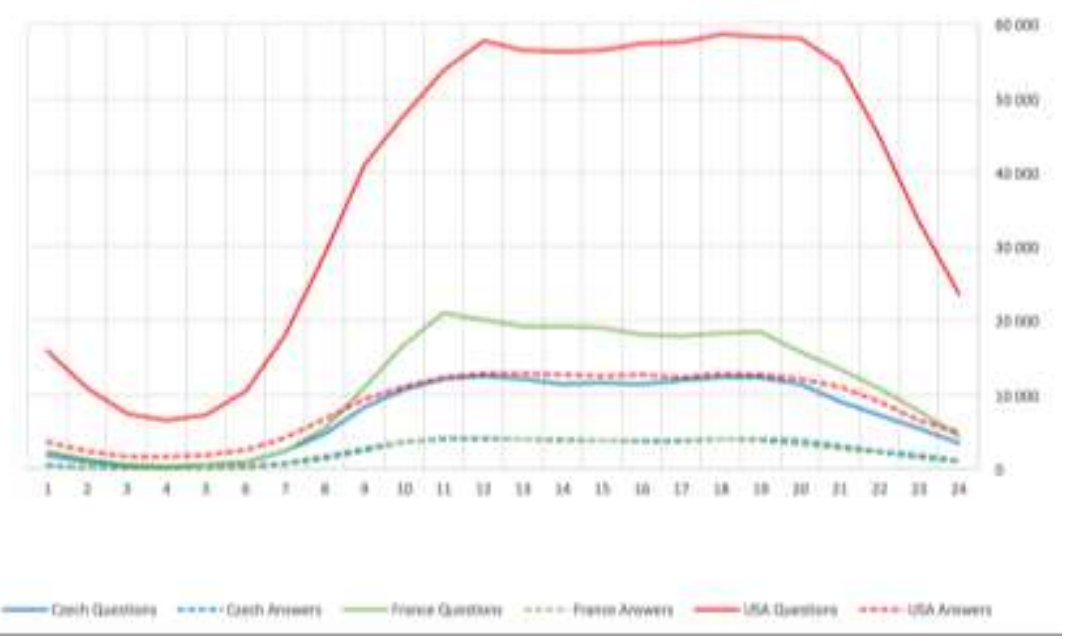

\subsection{Response time}

Figure 3 shows average delay of the first reaction on message during the day. The $\mathrm{x}$ axis reflects time when was message posted, y-axis describes the average response delay. Response time is crucial SCSR parameter, it expresses speed of reaction, responsibility, and reliability in any case or situation. The worst overall reaction time during the day has SFR in France with an average of 24 hours (with best average reaction takes more than 9 hours). There is a visible difference between French approach to SCRM and other markets.

Whereas an average response time in the Czech Republic and the USA varies between half an hour and three hours, MNOs in France are literally off the scope, beginning with SFR at about 6 hours and ending with Bouygues Telecom and Orange at over 12 hours. The highest peak was hit during the beginning of 2015 on SFR page with the average of over 84 hours (more than 3 and half days).

Generally, bad performance of French mobile operators seems to be caused by cultural differences, as all examined operators tend to perform similarly and obviously with no effect on a number of customers.

Czech and USA MNOs react within the same day. The slowest average reaction has been 9 hours and fastest comments appear in less than 60 minutes. The worst results are achieved at the midnight while constantly fastest reaction is during entire "office hours" from 5 a.m. until 9 p.m. The fastest average time of answers during the day performs around 3 p.m. and reaches 64 minutes. The slowest answers come from SFR in France: messages placed at midnight wait 41 hours and 45 minutes to be answered.

Secondly, we can see a stable trend of declining response time through all the operators in our study. Over the time, there are often clearly visible points, when certain operators started to pay more attention to Facebook customer care. This trend can be 
seen for example in the first half of 2013 on the page of Sprint, AT\&T did the same in the beginning of 2014. The same happened on the Czech market, surprisingly earlier than in the USA, Vodafone started that in early 2012, T-mobile CZ during 2012 and early 2013 whereas $\mathrm{O} 2 \mathrm{CZ}$ kept decent response time since the beginning of our data in 2011, but the overall winner would be the T-mobile USA with constantly prompt answers since 2012 .

Generally positive fact is, that operators tend to adapt to their customers' behaviour as they keep answering asked questions till late evening or even during the night and do not follow the typical 9 to 5 business day schedule.

Fig. 3. Average Response Delay of the First Answer (authors)

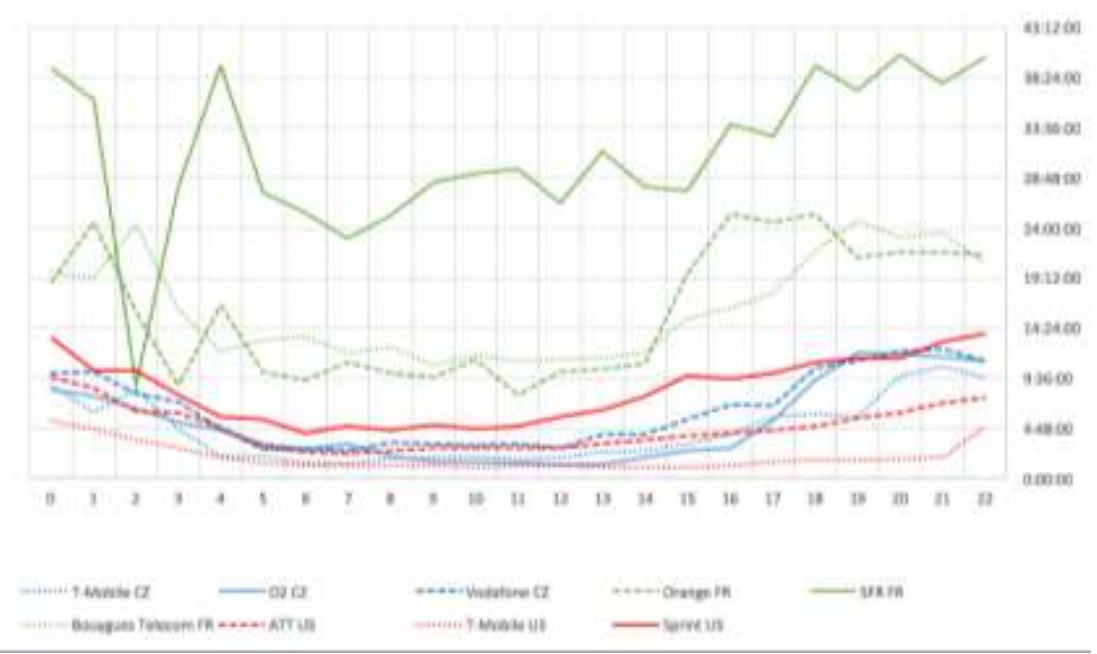

\subsection{Sentiment analysis}

As asked in the second Research question: "What mood / sentiment on SNS prevails? Is the medium predominantly negative?" For each MNO, we have analysed top 100 posts (900 in total) with the most shares and likes with results shown in the Fig. 4. Our findings confirm that Facebook is predominantly negative medium.

In the Czech Republic - majority $(56 \%)$ of the most popular post just identify problem areas and highlight particular "bad experience" and confirm negative reactions and statement offending the operator. The most frequent argument is the high price of contract packages comparing to Germany and Austria and the gap between the quality of service and its price. Second in frequency of likes are complaints focused on signal coverage. Billing errors proved to be a popular topic too - one customer even paid advertisement to promote his negative post.

In the USA discussion seems to be more extreme: users tend to like or dislike MNO, neutral posts are rare. Out of most shared\&liked posts only about $12 \%$ are neutral, $57 \%$ negative and $39 \%$ positive. Contrary to that, French users are neutral in almost half of cases (47\%), $45 \%$ are negative and just $8 \%$ are positive. 
Fig. 4. Positive / Negative Sentiment of Comments - in \% (authors)

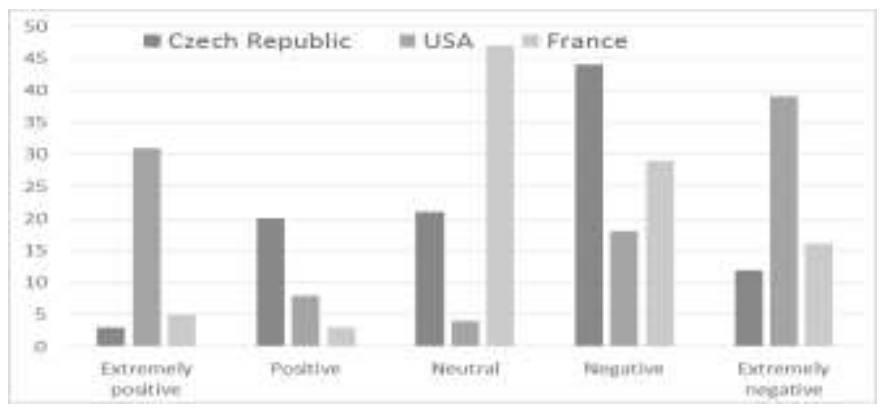

Table 3. TOP 100 Posts Evaluated on Positive/Negative Scale - in \% (authors)

\begin{tabular}{lccccc}
\hline Country & $\begin{array}{c}\text { Extremely } \\
\text { Positive }\end{array}$ & Positive & Neutral & Negative & $\begin{array}{c}\text { Extremely } \\
\text { Negative }\end{array}$ \\
\hline Czech Republic & 9 & 60 & 63 & 132 & 36 \\
USA & 93 & 24 & 12 & 54 & 117 \\
France & 15 & 9 & 141 & 87 & 48 \\
\hline
\end{tabular}

Our finding is consistent with the Galtung and Ruge's theory of News Values, where they identify negativity as one of the most attractive factors of media communication. [8]

\subsection{Enterprise Information System (EIS) and social media}

Developers have been quick to take the initiative, adding various social media packages to ERP systems. Let's have a look how the integration of social media with ERP or EIS should be constructed. If we integrate as additional input to the system social media stream (Facebook, Twitter, LinkedIn and others), we should than also consider, how to automatically analyse it.

The Data analysis phases should include Preprocessing, Representing Social Media Data in convenient form, Definition of some similarity metrics and result in the Clustering process. Text analysis platforms should be used, together with some relevant Ontologies.

As a result, we can benefit from various trend detections and visualisations, in the form of Patterns, Cluster results, Data Cubes or Graphs.

The matter is even more complicated by the fact, that most of above mentioned tools are language-related, so such automated system extremely difficult localize for small markets (simple translation does not work). 


\section{Conclusions}

We have proved, that Social CRM was in practice used quite extensively in 20122013 with declining number of user inputs lately. As we expected, mobile operators did their best to catch the trend of social networks and over time they clearly invested in improving the quality of customer care on Facebook (shortening the response time). There is still a possible opportunity to gain customers by good social CRM as none of the observed companies does perform ideally.

Our analysis also strongly suggested, that most of the social interactions are still being achieved "manually" - by customer care staff writing the posts. The timeline of interactions shows no signs of automated response system being used. Up-to-date Social CRM requires ever shorter response times, and probably the only way how to achieve it is the implementation of automated or computer aided SCRM processes. However, we admit, that such system would be a great challenge [4] to program into existing Enterprise Information Systems.

Lastly, we have proved, that Facebook is predominantly negative medium, where is quite difficult to perform a positive and successful SCRM.

Further research could be conducted to determine the effectiveness of SCRM in addressing diverse groups of Facebook users. Also, qualitative content analysis of the data we acquired would be interesting, albeit extremely time-consuming. In further paper, we should conduct on both quantitative and qualitative analysis of the data we have accumulated.

Acknowledgments. The paper was processed with the contribution of long-term support of scientific work on Faculty of Informatics and Statistics, University of Economics, Prague and help of the students in the course 4SA526 New Media.

\section{$7 \quad$ References}

1. Babinet, G., Orsenna, E.: Big Data, penser l'homme et le monde autrement. Le Passeur éditeur, Paris (2015).

2. Boehmova, L., Novak, R.: How Employers Use Linkedin for Hiring Employees in Comparison with Job Boards. In: Doucek, P. et al. (eds.) IDIMT-2015: Information Technology and Society Interaction and Interdependence. pp. 189-194 (2015).

3. Columbus, L.: Gartner Predicts CRM Will Be A \$36B Market By 2017 - Forbes, http://www.forbes.com/sites/louiscolumbus/2013/06/18/gartner-predicts-crm-willbe-a-36b-market-by-2017/\#633022d2c1ec.

4. Doucek, P.: E-Society - Perspectives and Risks for European Integration. In: Chroust, G. (ed.) IDIMT-2004. Universitatsverlag Rudolf Trauner, Linz (2004).

5. Dunaev, J., Stevens, R.: Seeking Safe Sex Information: Social Media Use, Gossip, and Sexual Health Behavior Among Minority Youth. J. Adolesc. Health. 58, 2, S93-S93 (2016). 
6. Erdos, F. et al.: The Benefit of It-Investments: Technological and Cost-ReturnBenefit Approach. In: Gerhard, C. et al. (eds.) IDIMT-2008. Universitatsverlag Rudolf Trauner, Linz (2008).

7. Facebook.com: Facebook Statistics, http://newsroom.fb.com/company-info/.

8. Galtung, J., Ruge, M.H.: The Structure of Foreign News. J. Peace Res. 2, 1, 64-91 (1965).

9. Pavlicek, A.: Social Media - the Good, the Bad, the Ugly. In: Doucek, P. et al. (eds.) IDIMT-2013: Information Technology Human Values, Innovation and Economy. pp. 139-149 (2013).

10. Sigmund, T.: Privacy in the Information Society: How to Deal with Its Ambiguity? In: Doucek, P. et al. (eds.) IDIMT-2014: Networking Societies - Cooperation and Conflict. pp. 191-201 (2014).

11. Soltani, Z., Navimipour, N.J.: Customer relationship management mechanisms: A systematic review of the state of the art literature and recommendations for future research. Comput. Hum. Behav. 61, 667-688 (2016).

12. Sudzina, F.: Escapist Motives for Playing Facebook Games: Fine-Tuning Constructs. In: Doucek, P. et al. (eds.) IDIMT-2013: Information Technology Human Values, Innovation and Economy. pp. 151-158 (2013).

13.Vondra, Z.: Explanation of Multimedia Communication Using Catwoe Analysis. In: Petr, D. et al. (eds.) IDIMT-2015: Information Technology and Society Interaction and Interdependence. pp. 311-318 (2015). 